\title{
A Fluorescence-Based Method for Rapid and Direct Determination of Polybrominated Diphenyl Ethers in Water
}

\author{
Huimei Shan, ${ }^{1,2}$ Chongxuan Liu,, ${ }^{1,2}$ Zheming Wang, ${ }^{2}$ Teng Ma, ${ }^{1,3}$ \\ Jianying Shang, ${ }^{2}$ and Duoqiang Pan ${ }^{2}$ \\ ${ }^{1}$ Laboratory of Basin and Wetland Eco-Restoration, China University of Geosciences, Wuhan 430074, China \\ ${ }^{2}$ Pacific Northwest National Laboratory, Richland, WA 99352, USA \\ ${ }^{3}$ State Key Laboratory of Biogeology and Environmental Geology, China University of Geosciences, Wuhan 430074, China \\ Correspondence should be addressed to Chongxuan Liu; chongxuan.liu@pnnl.gov and Teng Ma; mateng@cug.edu.cn
}

Received 15 October 2014; Revised 9 January 2015; Accepted 12 January 2015

Academic Editor: José B. Quintana

Copyright (C) 2015 Huimei Shan et al. This is an open access article distributed under the Creative Commons Attribution License, which permits unrestricted use, distribution, and reproduction in any medium, provided the original work is properly cited.

\begin{abstract}
A new method was developed for rapid and direct measurement of polybrominated diphenyl ethers (PBDEs) in aqueous samples using fluorescence spectroscopy. The fluorescence spectra of tri- to deca-BDE (BDE 28, 47, 99, 153, 190, and 209) commonly found in environment were measured at variable emission and excitation wavelengths. The results revealed that the PBDEs have distinct fluorescence spectral profiles and peak positions that can be exploited to identify these species and determine their concentrations in aqueous solutions. The detection limits as determined in deionized water spiked with PBDEs are 1.71-5.82 ng/L for BDE 28, BDE 47, BDE 190, and BDE 209 and 45.55-69.95 ng/L for BDE 99 and BDE 153. The effects of environmental variables including pH, humic substance, and groundwater chemical composition on PBDEs measurements were also investigated. These environmental variables affected fluorescence intensity, but their effect can be corrected through linear additivity and separation of spectral signal contribution. Compared with conventional GC-based analytical methods, the fluorescence spectroscopy method is more efficient as it only uses a small amount of samples $(2-4 \mathrm{~mL})$, avoids lengthy complicated concentration and extraction steps, and has a low detection limit of a few $\mathrm{ng} / \mathrm{L}$.
\end{abstract}

\section{Introduction}

Polybrominated diphenyl ethers (PBDEs) are emerging surface and groundwater contaminants that have received increasing public and regulatory scrutiny and thus research interest [1]. PBDEs are a class of organobromine compounds widely used as flame retardants (BFRs) that are commonly mixed into various industrial and household products including building materials, electronics, plastics, and foams. The BFRs become contaminants as they dissociate from such products and are released into environment [1]. Although PBDEs have been phased out in Europe and voluntarily withdrawn from the market in the US, they are still widely detected in soil, sediment, surface waters, air, animal, and human body [2-9]. PBDEs are lipophilic and hydrophobic with a strong affinity to solid materials. Despite this property, they are still detected in both surface water $[10,11]$ and groundwater [12]. Increasing evidences indicate that PBDEs are endocrine disruptors possessing toxicity to liver, thyroid, and neurodevelopment $[9,13-15]$.

The concentrations of PBDEs in aqueous samples are commonly determined using gas chromatography (GC) approaches with electron capture detector (ECD) [16], GC coupled to mass spectrometry (MS) with either negative chemical ionization (NCI) or electron impact (EI) as ionization techniques [17-19]. All these methods, however, require pretreatment of aqueous samples through solvent extraction, concentration, and purification. In addition, GCbased approach may be compromised when high-Br PBDEs congeners (e.g., BDE 209) degrade to low-Br PBDEs congeners at high temperature in chromatography column.

Here we report a new method to analyze PBDEs in water samples that can avoid the shortcomings in the GC-based approaches. The new method is based on characteristic 


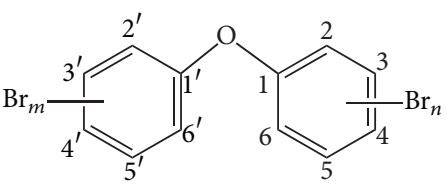

PBDEs $=\mathrm{C}_{12} \mathrm{H}_{(10-x)} \mathrm{Br}_{x} \mathrm{O}(x=1,2, \ldots, 10=m+n)$<smiles>Brc1ccc(Oc2ccc(Br)cc2Br)cc1</smiles>

BDE 28<smiles>Brc1ccc(Oc2cc(Br)c(Br)cc2Br)c(Br)c1</smiles>

BDE 99<smiles>Brc1ccc(Oc2c(Br)c(Br)c(Br)c(Br)c2Br)cc1Br</smiles>

BDE 190<smiles>Brc1ccc(Oc2ccc(Br)cc2Br)c(Br)c1</smiles>

BDE 47<smiles>Brc1cc(Br)c(Oc2cc(Br)c(Br)cc2Br)cc1Br</smiles>

BDE 153<smiles>Brc1c(Br)c(Br)c(Oc2c(Br)c(Br)c(Br)c(Br)c2Br)c(Br)c1Br</smiles>

BDE 209

FIgURE 1: The chemical structures of six major PBDEs including BDE 28, BDE 47, BDE 99, BDE 153, BDE 190, and BDE 209.

fluorescence properties of PBDEs under room temperature. Although fluorescence-based methods have been widely used in analyzing hydrophobic organic compounds in aqueous phase [20-23], sediments [24, 25], and engineered nanoporous materials [26], its application to analyze PBDEs has not been reported to our knowledge. The major objectives of this study are therefore to (1) characterize fluorescent properties of six major PBDEs congeners that are commonly found in environment and (2) demonstrate the efficacy of the fluorescence spectroscopy method for measuring the concentrations of PBDEs in aqueous samples. The new method was also compared with the GC-based approaches (GC-ECD and GC-EI-MS) to identify the advantages and disadvantages of the approaches.

\section{Materials and Methods}

2.1. Chemicals. Six congeners of PBDEs including 2,4,4' -tribromodiphenyl ether (BDE 28), 2,2',4,4' -tetrabromodiphenylether (BDE 47), 2,2',4,4',5-pentabromodiphenyl ether (BDE 99), 2,2' $4,4^{\prime} 5,5^{\prime}$-hexabromodiphenyl ether (BDE 153), $2,3,3^{\prime}, 4,4^{\prime}, 5,6$-heptabromodiphenyl ether (BDE 190), and decabromodiphenyl ether (BDE 209) were purchased from AccuStandard (New Haven, CT, USA). Their chemical structures are provided in Figure 1. The stock solutions of these chemicals $\left(1 \times 10^{6} \mathrm{ng} / \mathrm{L}\right)$ were prepared by mixing $1 \mathrm{~mL}$ PBDEs $\left(5 \times 10^{7} \mathrm{ng} / \mathrm{L}\right.$ in isooctane $)$ and $49 \mathrm{~mL}$ ethanol solution $(\geq 99.5 \%$, Fisher Scientific). The high mass ratio of ethanol used in the stock solution is to guarantee that the PBDEs and isooctane will completely mix with water in preparing standard solutions as described below. The stock solutions were diluted using deionized water (DI water) to prepare work solutions of $1000 \mathrm{ng} / \mathrm{L}$ for tri- to hexa-BDE and $100 \mathrm{ng} / \mathrm{L}$ for hepta- and deca-BDE, which were then used to prepare series of standard solutions of $1000,200,40,8,1.6,0.32$, and $0.064 \mathrm{ng} / \mathrm{L}$ for tri- to hexa-BDE and 100, 50, 25, 5, 1, 0.2 , and $0.04 \mathrm{ng} / \mathrm{L}$ for hepta- and deca-BDE in DI water. Humic acid was purchased from Fisher Scientific ( $\geq 90 \%$, MP Biomedicals) and used as received. $0.2 \mathrm{~g} / \mathrm{L} \mathrm{HA}$ solution was obtained by dissolving $0.2 \mathrm{~g}$ humic acid in $1 \mathrm{~L}$ DI water by constant stirring for $48 \mathrm{~h}$.

2.2. Fluorescence Measurements. The fluorescence spectra of PBDEs in aqueous samples were recorded using a conventional fluorimeter (Fluorolog III, Horiba Jobin Yvon Inc., Edison, NJ) equipped with a $350 \mathrm{~W}$ xenon lamp in quartz cuvettes $(3 \mathrm{~mL})$ and a Hamamatsu R928 photomultiplier tube at $-950 \mathrm{~V}$. The excitation wavelength $\left(\lambda_{\text {exc }}, \mathrm{nm}\right)$ was varied from 240 to $360 \mathrm{~nm}$ and emission wavelength $\left(\lambda_{\mathrm{em}}, \mathrm{nm}\right)$ was from 350 to $580 \mathrm{~nm}$ in intervals of $1 \mathrm{~nm}$ and exposure time of 0.1 second. Linear correlation of the intensity or integral areas of the characteristic fluorescence peaks with corresponding PBDEs concentrations was then established for each PBDEs congener and the detection limit was determined for the method. 


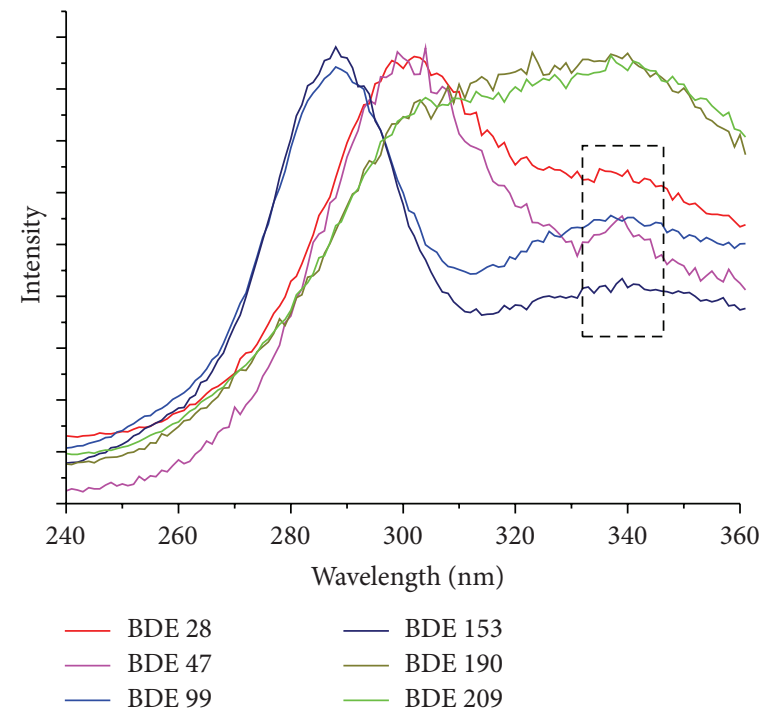

(a)

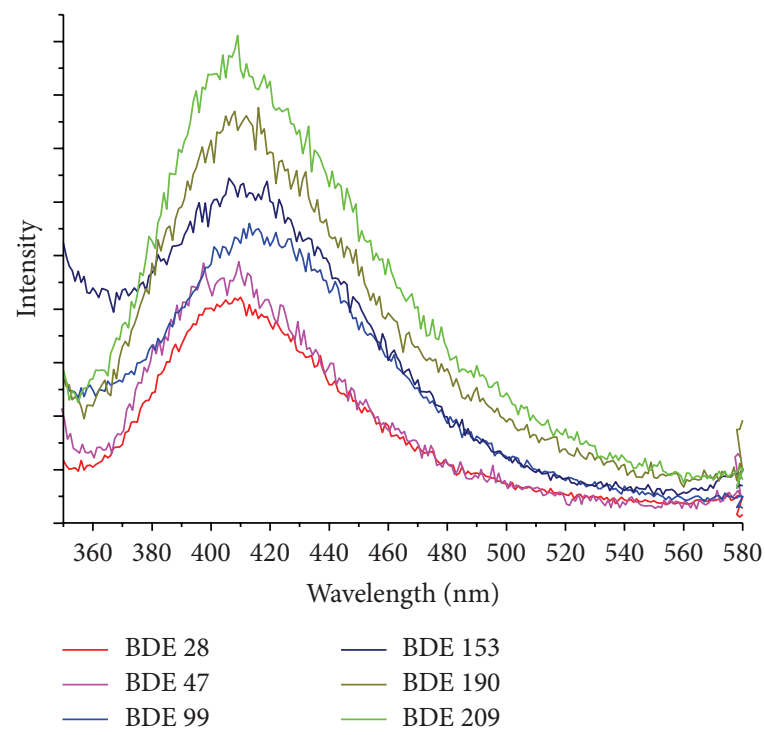

(b)

Figure 2: Excitationspectra (a) and emission spectra (b) of BDE 28, BDE 47, BDE 99, BDE 153, BDE 190, and BDE 209. The excitation spectra were collected at the emission wavelength $\left(\lambda_{\mathrm{em}}\right)$ of $440 \mathrm{~nm}$ and the emission fluorescence spectra were collected at excitation wavelength $\left(\lambda_{\text {exc }}\right)$ of $302 \mathrm{~nm}$.

2.3. Effects of Environmental Variables on Fluorescence Measurement. The effects of $\mathrm{pH}$ and humic substance on the fluorescence method were evaluated using BDE 47. BDE 47 was selected because it is the predominant congener of PBDEs in surface and groundwaters with a concentration ranging from $\mathrm{pg} / \mathrm{L}$ to tens of $\mathrm{ng} / \mathrm{L}[2,10,11,27,28]$. The $\mathrm{pH}$ in the PBDEs solutions was adjusted by acid-base titration using $1 \mathrm{mM} \mathrm{HCl}$ or $1 \mathrm{mM} \mathrm{NaOH}$. The effect of humic substance on fluorescence measurements was evaluated by successively adding aliquots of $200 \mathrm{mg} / \mathrm{L}$ humic acid in BDE 47 solutions.

2.4. Effect of Groundwater Chemical Composition. Synthetic groundwater (SGW) with the same chemical composition as that in groundwater at the U.S. Department of Energy's Hanford site, Washington State $\mathrm{pH} 8.1$ and ionic strength $6.3 \mathrm{mM}$ ) [29], was used as a background solution instead of DI water to evaluate the potential interference of inorganic groundwater chemical constituents on PBDEs fluorescence measurements. BDE 47 stock solution $\left(1 \times 10^{6} \mathrm{ng} / \mathrm{L}\right)$ was mixed into the SGW to prepare a series of solutions ranging from 64 to $200 \mathrm{ng} / \mathrm{L}$ of BDE 47 . The resulting solutions were stirred for more than $10 \mathrm{~h}$ with the sample containers wrapped with aluminum foil to avoid light exposure. After mixing, the solutions were measured to establish the relationship between fluorescence intensity and BDE 47 concentration in SGW. The relationship was compared to that derived in DI water to evaluate the effect of background inorganic solution chemistry on the PBDEs measurements.

\section{Results and Discussion}

3.1. Fluorescence Characteristics of PBDEs. The excitation spectra of the PBDEs recorded at fluorescence emission wavelength $\left(\lambda_{\mathrm{em}}\right)$ of $440 \mathrm{~nm}$ (Figure 2(a)) show behavior of three groups: 2,4,4'-tribromodiphenyl ether (BDE 28) and 2,2 $, 4,4^{\prime}$-tetrabromodiphenyl ether (BDE 47) formed the first group, which displays a major peak near $\lambda_{\mathrm{exc}}=$ $302 \mathrm{~nm} ; 2,2^{\prime}, 4,4^{\prime}, 5$-pentabromodiphenyl ether (BDE 99) and $2,2^{\prime}, 4,4^{\prime}, 5,5^{\prime}$-hexabromodiphenyl ether (BDE 153) formed the second group with a major peak near $\lambda_{\mathrm{exc}}=289 \mathrm{~nm}$; $2,3,3^{\prime}, 4,4^{\prime}, 5,6$-heptabromodiphenyl ether (BDE 190) and decabromodiphenyl ether (BDE 209) formed the third group with a plateau from $\lambda_{\text {exc }}=320$ to $340 \mathrm{~nm}$. A minor peak near $\lambda_{\text {exc }}=335$ was also observed for PBDEs with small number of bromine (BDE 28, BDE 47, BDE 99, and BDE 153) (Figure 2(a)). The behavior of the fluorescence excitation spectra of the three groups was also observed at other emission wavelengths (data not shown). These results indicated that the number and position of $\mathrm{Br}$ on the benzene rings of $3,3^{\prime}, 5,6$ (Figure 1) affected the excitation features of PBDEs apparently through influencing the original conjugated $\pi$ or $p-\pi$ system [30]. On the other hand, the result that PBDEs congeners within each group have similar spectra indicating that $\mathrm{Br}$ substituent position of $2^{\prime}, 5^{\prime}$ and $6^{\prime}$ on the benzene rings (Figure 1) apparently did not have the effect on the excitation spectrum. The major peak position in each excitation spectrum was provided in Table 1 for different PBDEs at different emission wavelengths.

The emission spectra of PBDEs at variable excitation wavelengths $\left(\lambda_{\text {exc }}=289,302,320\right.$, and $\left.340 \mathrm{~nm}\right)$ were also collected, and Figure 2(b) shows an example of the emission spectra collected at $\lambda_{\text {exc }}=302 \mathrm{~nm}$. Emission spectra collected at other excitation wavelengths were similar (data not shown). Figure 2(b) shows that six PBDEs have similar emission fluorescence spectra, displaying a large peak near $\lambda_{\mathrm{em}}=407$ to $420 \mathrm{~nm}$. The emission peak positions generally 
TABLE 1: The excitation and emission peak positions $\left(\lambda_{\max }, \mathrm{nm}\right)$ of six single congeners of PBDEs at variable emission wavelengths $\left(\lambda_{\mathrm{em}}=\right.$ $380,405$, and $440 \mathrm{~nm})$ and excitation wavelengths $\left(\lambda_{\text {exc }}=289,302,320\right.$, and $\left.340 \mathrm{~nm}\right)$.

\begin{tabular}{|c|c|c|c|c|c|c|c|}
\hline \multirow{2}{*}{ PBDEs } & \multicolumn{3}{|c|}{ Excitation spectra } & \multicolumn{4}{|c|}{ Emission spectra } \\
\hline & $\left(\lambda_{\max }, 380 \mathrm{~nm}\right)$ & $\left(\lambda_{\max }, 405 \mathrm{~nm}\right)$ & $\left(\lambda_{\max }, 440 \mathrm{~nm}\right)$ & $\left(\lambda_{\max }, 289 \mathrm{~nm}\right)$ & $\left(\lambda_{\max }, 302 \mathrm{~nm}\right)$ & $\left(\lambda_{\max }, 320 \mathrm{~nm}\right)$ & $\left(\lambda_{\max }, 340 \mathrm{~nm}\right)$ \\
\hline BDE 28 & 300,380 & 302,405 & 302,440 & 403,289 & 409,302 & 412,320 & 436,340 \\
\hline BDE 47 & 300,380 & 300,405 & 302,440 & 408,289 & 407,302 & 406,320 & 434,340 \\
\hline BDE 99 & 289,380 & 289,405 & 289,440 & 412,289 & 413,302 & 412,320 & 423,340 \\
\hline BDE 153 & 289,380 & 289,405 & 289,440 & 419,289 & 420,302 & 427,320 & 429,340 \\
\hline BDE 190 & 302,380 & 314,405 & 323,440 & 425,289 & 418,302 & 422,320 & 445,340 \\
\hline BDE 209 & 302,380 & 305,405 & 337,440 & 412,289 & 408,302 & 429,320 & 445,340 \\
\hline
\end{tabular}

shifted right with increasing excitation wavelength (Table 1). Minor difference in emission peak position, however, exists for different PBDEs and the difference in their peak positions changes with excitation wavelength (Table 1). These properties, in combination with excitation spectra, can be used to distinguish different congeners in aqueous samples.

3.2. Linearity, Reproducibility, and Repeatability. The peak intensity and area in the fluorescence emission spectra were used to establish their relationships with PBDEs concentrations. In the data analysis, the fluorescence intensity or spectral area $\left(I_{F}\right.$ or $\left.\sum I_{F}\right)$ was calculated as follows:

$$
I_{F}=I_{F i}-I_{F o}
$$

or

$$
\sum I_{F}=\sum I_{F i}-\sum I_{F o}
$$

where $I_{F i}$ is the fluorescence peak intensity and $I_{F o}$ is the fluorescence intensity for background solvent. $\sum I_{F i}$ is the area surrounding a characteristic fluorescence peak, and $\sum I_{F o}$ is the area for background solvent.

Figure 3 shows an example of the correlation between emission peak intensity or area and corresponding concentration of PBDEs measured at $\lambda_{\text {exc }}=302 \mathrm{~nm}$ using BDE 47 as the example. The strength or the area of the emission spectra peak increased with increasing PBDEs concentration. A good linearity was observed using either the spectral areas $\left(R^{2}=\right.$ $0.9996)$ or the spectral peak intensity $\left(R^{2}=0.9996\right)$. The linearity was observed for all other studied PBDEs congeners (BDE 28, BDE 99, BDE 153, BDE 190, and BDE 209) (spectra not shown). In addition, replicate sample analyses indicated that the method has a good reproducibility with mean relative standard deviation values lower than $4.74 \%$ in all cases.

3.3. Limit of Detection (LOD). The detection limits were calculated as three times the standard deviation of ten replicate samples at concentration near the detection limit [31]. The calculated detection limits of $\mathrm{BDE} 28, \mathrm{BDE} 47, \mathrm{BDE}$ 99, BDE 153, BDE 190, and BDE 209 were 5.82, 2.70, 69.95, $45.55,1.71$, and $3.81 \mathrm{ng} / \mathrm{L}$, respectively.

3.4. Effect of $\mathrm{pH}$ on Fluorescence Measurement. Solution $\mathrm{pH}$ may affect fluorescence intensity of organic compounds [3234]. Figure 4(a) shows that the fluorescence intensity of BDE
47 (50 ng/L in DI water) increased linearly with increasing $\mathrm{pH}$, indicating that $\mathrm{pH}$ affects PBDEs measurements. The effect of $\mathrm{pH}$ on fluorescence intensity of organic compounds is typically attributed to the ionization effect [35] and the subsequent alternation of molecular structures of fluorophores. The effect of ionization is known to disappear near and above $\mathrm{pH}$ neutrality [36]. The consistent increase in fluorescence intensity with increasing $\mathrm{pH}$ (below and above the neutrality) (Figure 4(a)) suggested that the $\mathrm{pH}$ effect on the PBDE fluorescence properties was most likely caused by the changes in molecular configuration. Ghosh and Schnitzer [37] found that organic matter (e.g., humic substances) has a linear structure at high $\mathrm{pH}$ and forms coils when $\mathrm{pH}$ decreases. The coil structure may mask some internal fluorophores, leading to lower fluorescence emission at lower $\mathrm{pH}$. At a higher $\mathrm{pH}$, the configuration becomes linear and masked fluorophores are exposed to fluoresce, which increases the fluorescence intensity. The coil structure may be induced by strong $\mathrm{H}$-bond between $\mathrm{H}^{+}$and the fluorophores within the HA molecule. Such effect would be more pronounced at lower $\mathrm{pH}$, where abundant $\mathrm{H}^{+}$is available to form the $\mathrm{H}$ bond. As $\mathrm{pH}$ increased (and $\left[\mathrm{H}^{+}\right]$drops), fewer $\mathrm{H}$-bonds were formed and the deexcitation effect becomes weaker, leading to increased fluorescence intensity. The $\mathrm{pH}$ effect on the fluorescence intensity of PBDEs was fully reversible with increasing and decreasing $\mathrm{pH}$ cycles.

While $\mathrm{pH}$ affects PBDEs fluorescence intensity, the linear correlation between the fluorescence intensity and its concentration was held at all PBDE concentrations examined (Figure 4(b)). In other words, solution $\mathrm{pH}$ only affected the slope of the linear correlation curves between the fluorescence intensity and PBDEs concentration; the linear calibration curves are all valid at different $\mathrm{pH}$, while the slope of the liner curves could be corrected at any given solution $\mathrm{pH}$. These results indicated that solution $\mathrm{pH}$ is an important factor to consider in establishing calibration curve and/or adjusting $\mathrm{pH}$ in $\mathrm{PBDEs}$ samples in applying fluorescence method.

3.5. Effect of Humic Acid on Fluorescence Measurement. Humic substances, which contain fluorescent functional groups, are expected to interfere with the fluorescent determination of organic contaminants in aqueous samples [21, 23, 38-40]. Figure 5 shows that when the concentration of humic acid (HA) is $10^{4}$ time that of BDE 47 , the measured overall fluorescence intensity at the emission maximum of BDE 47 

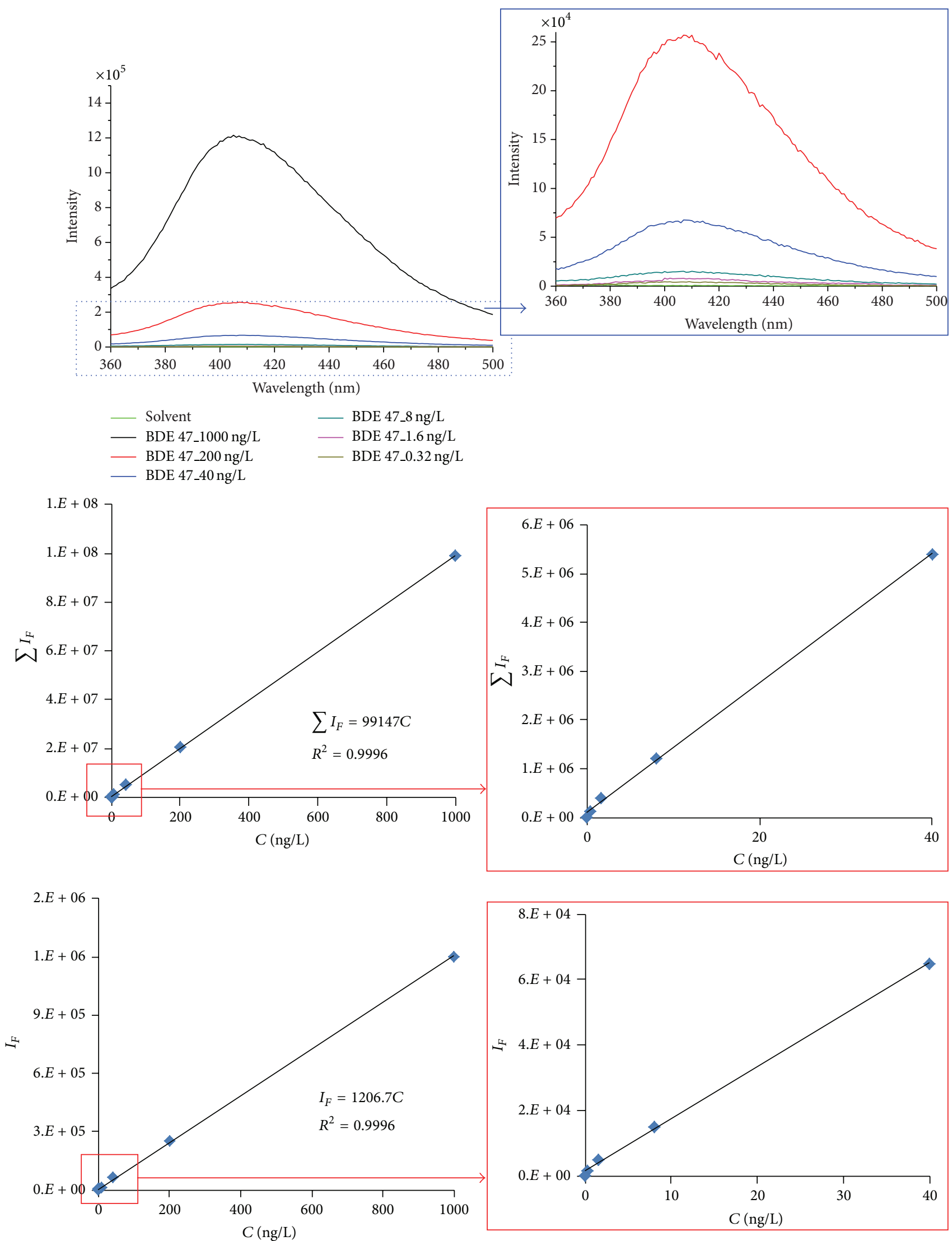

Figure 3: Emission spectra $\left(\lambda_{\text {exc }}=302 \mathrm{~nm}\right)$ as a function of BDE 47 concentration $(0.32 \mathrm{ng} / \mathrm{L}$ to $1000 \mathrm{ng} / \mathrm{L})$. The figure inserts show the linear correlation between the peak intensity $I_{F}$ (at $406 \mathrm{~nm}$ ) or peak area $\sum I_{F}$ (from 360 to $500 \mathrm{~nm}$ ) with BDE 47 concentration. 


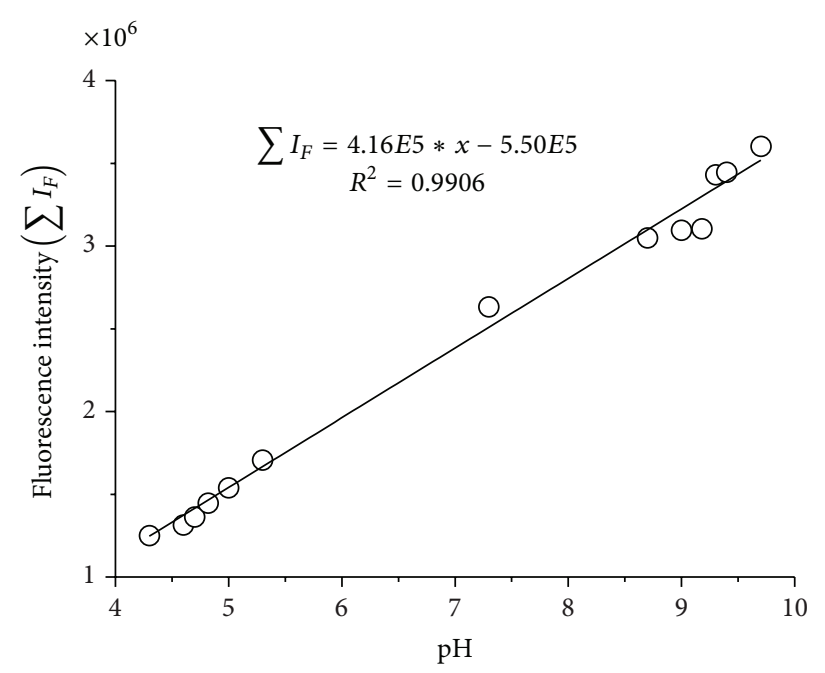

(a)

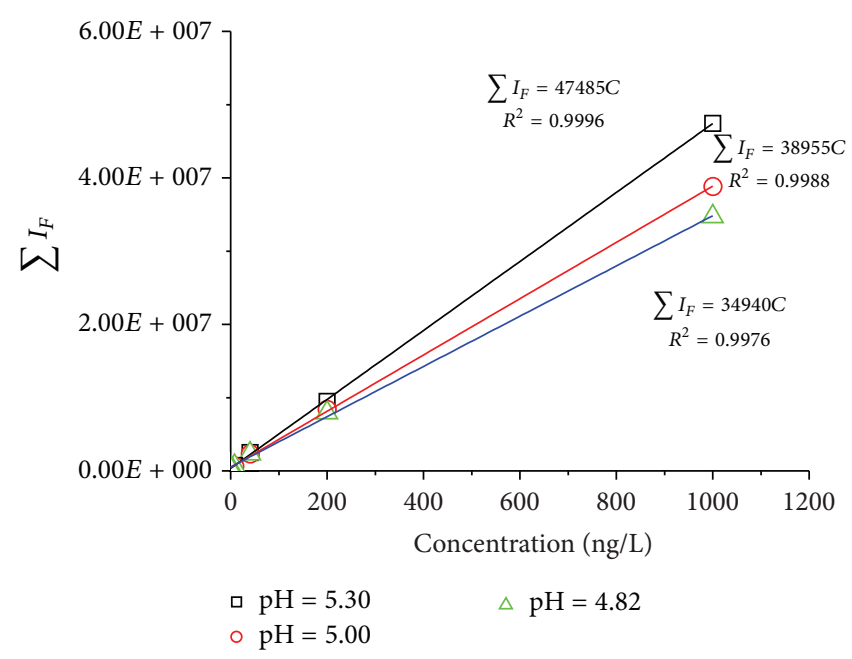

(b)

FIGURE 4: Fluorescence intensity $\left(\sum I_{F 360 \sim 500 \mathrm{~nm}}\right)$ variations of $50 \mathrm{ng} / \mathrm{L} \mathrm{BDE} 47$ as a function of $\mathrm{pH}(\mathrm{a})$ and the influence of $\mathrm{pH}$ on the slope of the linear correlations between the fluorescence intensity and BDE 47 concentration (b).

$(\sim 408 \mathrm{~nm}$ ) increased from 40,000 (a.u) to $\sim 62,000$ (a.u); that is, the net contribution from HA emission intensity was about half of that of BDE 47 (Figure 5). Therefore, any interference of fluorescence measurement of BDE 47 from HA will likely be insignificant or can be properly corrected at HA concentration levels $<10^{4}$ times that of BDE 47 . However, due to the partial overlap of the emission spectra of BDE 47 and that of humic acid (HA), the overall emission intensity of the BDE 47 and HA mixtures increased and the spectra became broader when HA concentration was further increased in solution (Figure 5). At such HA concentrations, the coexistence of HA and PBDEs significantly affected the fluorescence strength as revealed by lower fluorescence intensity in the mixed HA and PBDEs solutions than that in the solutions containing HA only when HA concentration was above $0.5 \mathrm{mg} / \mathrm{L}$ (Figure 5 insert). The linear relationship, however, still exists showing the overall fluorescence intensity increased with increasing HA concentration, suggesting that the fluorescence signal contribution from HA and PBDEs can be separated.

Assume that the measured fluorescence intensity of PBDEs solution containing HA is the sum of those from both PBDEs and $\mathrm{HA}$, as follows,

$$
\sum I_{F m}=a * \sum I_{F 1}+b * \sum I_{F 2}
$$

where $\sum I_{F m}$ is the measured peak area jointly contributed from PBDEs and HA, $\sum I_{F 1}$ is the fluorescence peak area contributed from PBDEs only and $\sum I_{F 2}$ is contributed from HA only, and $a$ and $b$ are the fitting parameters. By fitting the measured spectral data (Figure 5), $a$ and $b$ were determined to be 0.96 and 0.08 for $\mathrm{BDE} 47$ solutions, respectively.

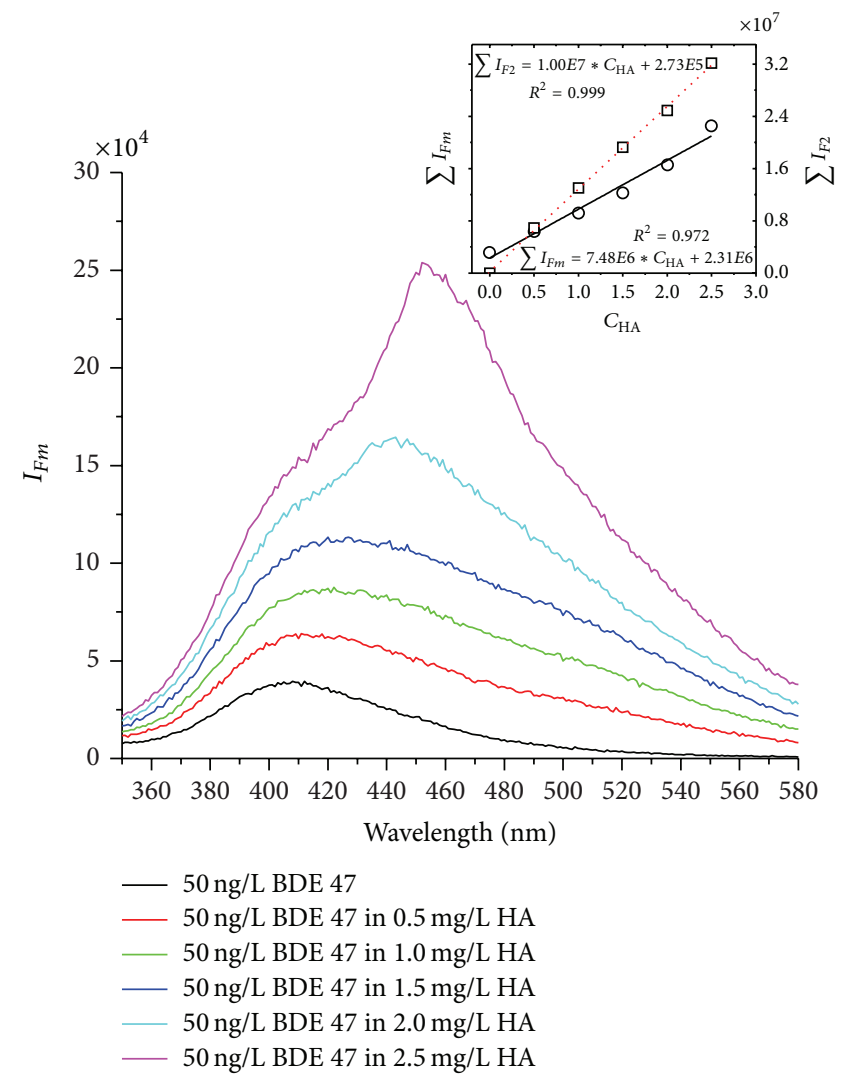

FIGURE 5: Fluorescence spectra of solutions containing mixed BDE 47 and HA. The figure inserts show the linear correlations of fluorescence intensity as a function HA concentration in solutions with and without BDE 47. 


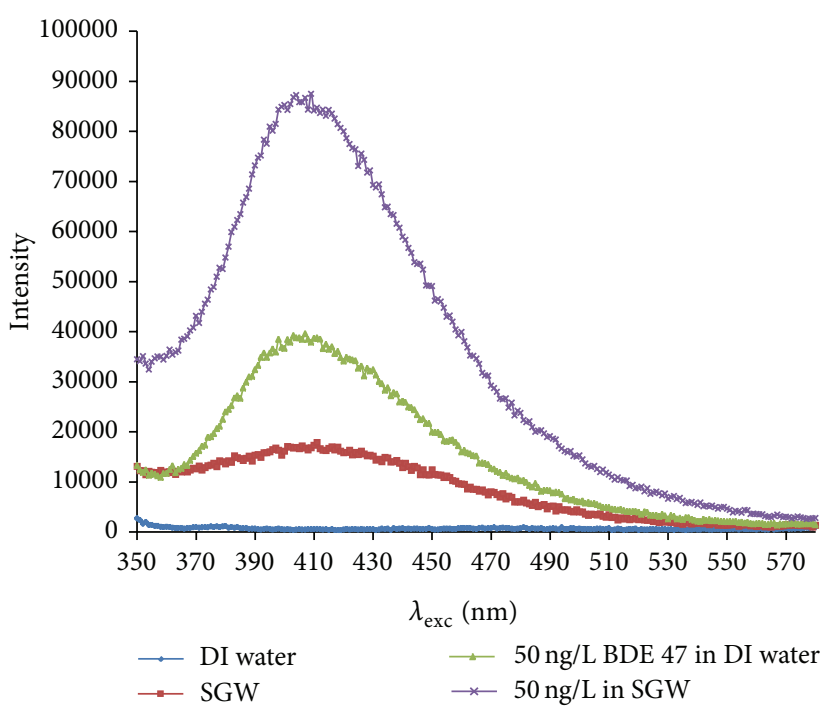

(a)

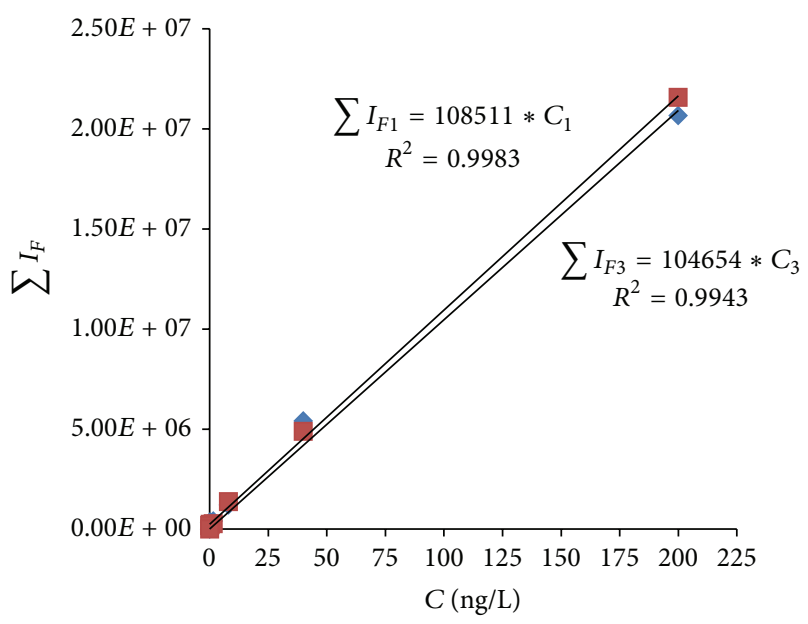

- BDE 47 in DI water

BDE 47 in SGW

(b)

FIGURE 6: The effect of SGW on the fluorescence spectra of BDE 47 (a) and linear correlations between fluorescence intensity and BDE 47 concentrations (b).

A large $a$ value and a small $b$ value suggest that PBDEs had a stronger effect on HA fluorescence signal than the HA on PBDEs fluorescence. Considering that HA concentrations in environmental waters for a given area during a defined period of time in a year are relatively stable and can be properly measured based on total organic carbon concentrations, it is possible that the effect of HA on PBDEs quantification at HA concentration $\geq 10^{4}$ times that of PBDEs can be properly estimated and corrected.

3.6. Effect of Groundwater Chemical Composition. Fluorescencemeasurement of PBDEs in groundwater may also be affected by other chemical constituents such as metal cations and inorganic anions [23]. To investigate such potential interference, fluorescence spectral measurements of a series of solutions with different BDE 47 concentrations in SGW were performed. Figure 6 shows that fluorescence intensity of BDE 47 was only slightly enhanced (3.7\%) in SGW compared to that in DI water, due to some unidentified interactions between BDE 47 and other chemical species present in the groundwater. Apparently, the effect of groundwater composition on BDE 47 determination was minor giving the close calibration curves in DI water and SGW after the background fluorescence signal from the SGW was removed.

3.7. Comparison with Conventional Method. GC methods are commonly used in measuring PBDEs in aqueous solutions. Prior to GC analysis, the target PBDEs compounds must be first extracted from water samples using continuous liquid/liquid extraction (CLLE), solid-phase extraction (SPE), or separation funnel extraction (SFE) [41]. Such extraction processes not only take time $(20-60 \mathrm{~min})$, but also create recovery problems that often lead to underestimation of the target compounds $[42,43]$. In addition, after extraction, the low concentration PBDEs compounds have to be further concentrated and then used for PBDEs measurement by
GC-ECD or GC-MS [41]. The fluorescence method described here had the similar LOD as GC or GC-EI-MS (low to a few $\mathrm{ng} / \mathrm{L}$ ) but showed great advantages with rapid (about $1 \mathrm{~min}$ ) and direct measurement that avoids lengthy extraction steps and guarantees $100 \%$ recovery. In addition, the new method only requires a small amount $(2-4 \mathrm{~mL}$ ) of sample (Table 2) and eliminated the use of any other organic solvents as well as separation and concentration procedures.

It should be pointed out that although individual congeners of PBDEs show characteristic fluorescence peaks at different excitation and emission wavelengths, when more than one congener of PBDEs are present, the corresponding emission spectra will overlap (Table 1). This may be a challenge to unambiguously identify individual PBDEs species in aqueous samples containing mixed PBDEs congeners. Thus, identification and quantification of individual PBDEs congeners will require spectral deconvolution or prior knowledge of the types of PBDEs present. Secondly, the method has to correct the effect of environmental variables such as $\mathrm{pH}$ and HA and potential other fluorescence-emission chemicals with similar excitation and emission peaks. Nevertheless, the fast analysis and $100 \%$ recovery of the new method can be ideal for mechanistic study with known background solution chemical composition and under controlled environmental conditions. Under such conditions, quantitative spectral analyses are possible as the concentrations of interfering fluorescence species are well-defined. In addition, the fluorescence-based approach opens a way to design in situ observation systems and on-line detection systems to rigorously study $\mathrm{PBDE}$ reactive transport in flow through systems such as in columns and flow cells [22, 26, 44].

\section{Conclusions and Implication}

This study developed a new method for rapid and direct measurements of PBDEs in aqueous samples using fluorescence 
TABLE 2: Comparison of fluorescence and GC or GC-EI-MS for determining PBDEs in aqueous solutions.

\begin{tabular}{|c|c|c|c|c|c|c|c|}
\hline Methods & Congener & $\begin{array}{c}\text { Linearity range } \\
(\mathrm{ng} / \mathrm{L})\end{array}$ & Sample and volume & $\begin{array}{c}\text { Extraction } \\
\text { method }^{*}\end{array}$ & $\begin{array}{c}\text { Recovery } \\
(\%)\end{array}$ & $\begin{array}{c}\mathrm{LOQ}^{\mathrm{a}} / \mathrm{LOD}^{\mathrm{b}} \\
(\mathrm{ng} / \mathrm{L})\end{array}$ & $\begin{array}{c}\text { Mesurement } \\
\text { time (min) }\end{array}$ \\
\hline \multirow[b]{2}{*}{ GC-EI-MS } & $\begin{array}{c}\text { Tri- to hexa-BDE } \\
{[43]}\end{array}$ & $20-600$ & $100 \mathrm{~mL}$ surface water & SBSE & 99-106 & $\begin{array}{c}1-32^{\mathrm{a}} \\
0.4-9.6^{\mathrm{b}}\end{array}$ & 56.69 \\
\hline & $\begin{array}{l}\text { BDE } 47,99,100 \text {, } \\
\text { and } 153[42]\end{array}$ & $4-150$ & $\begin{array}{l}10 \mathrm{~mL} \text { ultrapure water } \\
\text { spiked with } 10 \mathrm{ng} / \mathrm{L} \\
\text { PBDEs }\end{array}$ & $\mathrm{CPE}$ & 99-106 & $1-2^{\mathrm{b}}$ & 15.50 \\
\hline GC-ECD & $\begin{array}{c}\text { BDE } 28,47,85,99, \\
100, \\
153 \text {, and } 154[45]\end{array}$ & $\begin{array}{l}0.1-100 \text { for BDE } 28, \\
47 ; \\
0.5-500 \text { for others }\end{array}$ & $\begin{array}{l}5 \mathrm{~mL} \text { Ultra Milli-Q } \\
\text { water spiked with } \\
\text { stock solution of } \\
\text { PBDEs }\end{array}$ & $\begin{array}{l}\text { SPE- } \\
\text { DLLME }\end{array}$ & $72-100$ & $0.03-0.15^{\mathrm{b}}$ & 36.67 \\
\hline \multirow[t]{2}{*}{$\begin{array}{l}\text { UV- } \\
\text { fluorescence }\end{array}$} & $\begin{array}{l}\text { BDE } 28,47,190, \\
\quad \text { and } 209^{\neq}\end{array}$ & $\begin{array}{l}0.32-1000 \text { for BDE } \\
28 ; \\
0-1000 \text { for BDE } 47 \\
0.2-50 \text { for BDE } \\
190 ; \\
0.04-100 \text { for BDE } \\
209 ;\end{array}$ & $\begin{array}{l}4 \mathrm{~mL} \text { DI water spiked } \\
\text { with stock solution of } \\
\text { PBDEs }\end{array}$ & No need & 100 & $1.71-5.82^{\mathrm{b}}$ & 1 \\
\hline & BDE 99 and $153^{\neq}$ & $0.064-2000$ & & & & $45.55-69.95^{\mathrm{b}}$ & 1 \\
\hline
\end{tabular}

*SBSE, stir bar sorptive extraction; CPE, cloud point extraction; HS-SPME, headspace solid-phase microextraction; SPE-DLLME, solid-phase extractiondispersive liquid-liquid microextraction; GC-ITD-MS/MS, gas chromatography-ion trap tandem mass spectrometry.

${ }^{\neq}$In this study calculated by $I_{F(406 \mathrm{~nm})}=a_{1} * C+b_{1}$.

${ }^{\mathrm{a}}$ The limit of quantification (LOQ). ${ }^{\mathrm{b}}$ The limit of detection (LOD).

spectroscopy. Results showed that tri- to deca-BDE (BDE 28, BDE 47, BDE 99, BDE 153, BDE 190, and BDE 209) that are commonly present in surface and groundwaters have distinct fluorescence spectra and peak positions that can be exploited to identify these species and determine their concentrations in aqueous solutions. Compared with conventional GC-based analytical methods, the fluorescence spectroscopy method is more efficient as it only uses a small amount of samples $(4 \mathrm{~mL})$, avoids lengthy concentration and extraction steps, and has a low detection limit: 1.71-5.82 ng/L for BDE 28, BDE 47, BDE 190, and BDE 209 and 45.55$69.95 \mathrm{ng} / \mathrm{L}$ for BDE 99 and BDE 153. The environmental variables including $\mathrm{pH}$ and $\mathrm{HA}$ contents can affect fluorescence intensity, but their effect can be corrected through proper spectral Deconvolution procedures if the interfering factors can be independently quantified. This method is particularly suitable for mechanistic studies of processes such as sorption and desorption and reactive transport of specific PBDEs species under controlled conditions. The method also has a potential for in situ investigation of reactive transport of PBDEs in porous media.

\section{Conflict of Interests}

The authors declare that there is no conflict of interests regarding the publication of this paper.

\section{Acknowledgments}

This research was supported by the Natural Science Foundation of China (no. 41372252). Part of this research was performed at Environmental Molecular Science Laboratory (EMSL), a national scientific user facility at Pacific Northwest
National Laboratory (PNNL) managed by the Department of Energy's Office of Biological and Environmental Research. Pacific Northwest National Laboratory is operated for the U.S. Department of Energy by Battelle under Contract DE-AC0676RLO 1830. The authors also thank the China Scholarship Council (no. 201206410015) for sponsoring Huimei Shan to conduct this cooperative research at PNNL. The authors thank the anonymous reviewers for constructive comments and suggestions.

\section{References}

[1] G. T. Yogui and J. L. Sericano, "Polybrominated diphenyl ether flame retardants in the U.S. marine environment: a review," Environment International, vol. 35, no. 3, pp. 655-666, 2009.

[2] C. A. de Wit, "An overview of brominated flame retardants in the environment," Chemosphere, vol. 46, no. 5, pp. 583-624, 2002.

[3] J. L. Domingo, "Polybrominated diphenyl ethers in food and human dietary exposure: a review of the recent scientific literature," Food and Chemical Toxicology, vol. 50, no. 2, pp. 238249, 2012.

[4] M. Gorga, E. Martínez, A. Ginebreda, E. Eljarrat, and D. Barceló, "Determination of PBDEs, HBB, PBEB, DBDPE, HBCD, TBBPA and related compounds in sewage sludge from Catalonia (Spain)," Science of the Total Environment, vol. 444, pp. 51-59, 2013.

[5] R. A. Hites, "Polybrominated diphenyl ethers in the environment and in people: a meta-analysis of concentrations," Environmental Science \& Technology, vol. 38, no. 4, pp. 945-956, 2004.

[6] J. Ma, X. Qiu, J. Zhang, X. Duan, and T. Zhu, "State of polybrominated diphenyl ethers in China: an overview," Chemosphere, vol. 88, no. 7, pp. 769-778, 2012. 
[7] F. Rahman, K. H. Langford, M. D. Scrimshaw, and J. N. Lester, "Polybrominated diphenyl ether (PBDE) flame retardants," Science of the Total Environment, vol. 275, no. 1-3, pp. 1-17, 2001.

[8] A. Sjödin, D. G. Patterson Jr., and A. Bergman, "A review on human exposure to brominated flame retardants-particularly polybrominated diphenyl ethers," Environment International, vol. 29, no. 6, pp. 829-839, 2003.

[9] T. Hamers, J. H. Kamstra, E. Sonneveld et al., "In vitro profiling of the endocrine-disrupting potency of brominated flame retardants," Toxicological Sciences, vol. 92, no. 1, pp. 157-173, 2006.

[10] M.-Y. Chen, M. Yu, X.-J. Luo, S.-J. Chen, and B.-X. Mai, “The factors controlling the partitioning of polybrominated diphenyl ethers and polychlorinated biphenyls in the water-column of the Pearl River Estuary in South China," Marine Pollution Bulletin, vol. 62, no. 1, pp. 29-35, 2011.

[11] R. C. Hale, M. Alaee, J. B. Manchester-Neesvig, H. M. Stapleton, and M. G. Ikonomou, "Polybrominated diphenyl ether flame retardants in the North American environment," Environment International, vol. 29, no. 6, pp. 771-779, 2003.

[12] J. Levison, K. Novakowski, E. J. Reiner, and T. Kolic, "Potential of groundwater contamination by polybrominated diphenyl ethers (PBDEs) in a sensitive bedrock aquifer (Canada)," Hydrogeology Journal, vol. 20, no. 2, pp. 401-412, 2012.

[13] P. O. Darnerud, "Toxic effects of brominated flame retardants in man and in wildlife," Environment International, vol. 29, no. 6, pp. 841-853, 2003.

[14] P. O. Darnerud, "Brominated flame retardants as possible endocrine disrupters," International Journal of Andrology, vol. 31, no. 2, pp. 152-160, 2008.

[15] A. P. Vonderheide, K. E. Mueller, J. Meija, and G. L. Welsh, "Polybrominated diphenyl ethers: causes for concern and knowledge gaps regarding environmental distribution, fate and toxicity," Science of the Total Environment, vol. 400, no. 1-3, pp. 425-436, 2008.

[16] J.-X. Wang, D.-Q. Jiang, Z.-Y. Gu, and X.-P. Yan, "Multiwalled carbon nanotubes coated fibers for solid-phase microextraction of polybrominated diphenyl ethers in water and milk samples before gas chromatography with electron-capture detection," Journal of Chromatography A, vol. 1137, no. 1, pp. 8-14, 2006.

[17] N. Fontanals, T. Barri, S. Bergström, and J.-Å. Jönsson, "Determination of polybrominated diphenyl ethers at trace levels in environmental waters using hollow-fiber microporous membrane liquid-liquid extraction and gas chromatography-mass spectrometry," Journal of Chromatography A, vol. 1133, no. 1-2, pp. 41-48, 2006.

[18] A. González-Gago, S. H. Brandsma, P. E. G. Leonards, J. De Boer, J. M. Marchante-Gayón, and J. I. Garcia Alonso, "Determination of ultra-trace levels of priority PBDEs in water samples by isotope dilution GC(ECNI)MS using 81Br-labelled standards," Analytical and Bioanalytical Chemistry, vol. 401, no. 8, pp. 2639-2649, 2011.

[19] M. G. Ikonomou, S. Rayne, M. Fischer, M. P. Fernandez, and W. Cretney, "Occurrence and congener profiles of polybrominated diphenyl ethers (PBDEs) in environmental samples from coastal British Columbia, Canada," Chemosphere, vol. 46, no. 5, pp. 649-663, 2002.

[20] J. Amador-Hernández, J. M. Fernández-Romero, and M. D. Luque de Castro, "Flow injection screening and semiquantitative determination of polycyclic aromatic hydrocarbons in water by laser induced spectrofluorimetry-chemometrics," Analytica Chimica Acta, vol. 448, no. 1-2, pp. 61-69, 2001.
[21] T. Baumann, S. Haaszio, and R. Niessner, "Applications of a laser-induced fluorescence spectroscopy sensor in aquatic systems," Water Research, vol. 34, no. 4, pp. 1318-1326, 2000.

[22] S. B. Hawthorne, R. W. St Germain, and N. A. Azzolina, "Laserinduced fluorescence coupled with solid-phase microextraction for in situ determination of PAHs in sediment pore water," Environmental Science and Technology, vol. 42, no. 21, pp. 80218026, 2008.

[23] S. M. Rudnick and R. F. Chen, "Laser-induced fluorescence of pyrene and other polycyclic aromatic hydrocarbons (PAH) in seawater," Talanta, vol. 47, no. 4, pp. 907-919, 1998.

[24] D. T. F. Kuo, R. G. Adams, S. M. Rudnick, R. F. Chen, and P. M. Gschwend, "Investigating desorption of native pyrene from sediment on minute- to month-timescales by time-gated fluorescence spectroscopy," Environmental Science \& Technology, vol. 41, no. 22, pp. 7752-7758, 2007.

[25] M. Lemke, R. Fernández-Trujillo, and H.-G. Löhmannsröben, "In-situ LIF analysis of biological and petroleum-based hydraulic oils on soil," Sensors, vol. 5, no. 1-2, pp. 61-69, 2005.

[26] J. Shang, C. Liu, Z. Wang et al., "In-situ measurements of engineered nanoporous particle transport in saturated porous media," Environmental Science \& Technology, vol. 44, no. 21, pp. 8190-8195, 2010.

[27] H.-B. Moon, M. Choi, J. Yu, R.-H. Jung, and H.-G. Choi, "Contamination and potential sources of polybrominated diphenyl ethers (PBDEs) in water and sediment from the artificial Lake Shihwa, Korea," Chemosphere, vol. 88, no. 7, pp. 837-843, 2012.

[28] G. Söderström, U. Sellström, C. A. De Wit, and M. Tysklind, "Photolytic Debromination of Decabromodiphenyl Ether (BDE 209)," Environmental Science \& Technology, vol. 38, no. 1, pp. 127-132, 2004.

[29] C. Liu, J. M. Zachara, N. P. Qafoku, and Z. Wang, "Scaledependent desorption of uranium from contaminated subsurface sediments," Water Resources Research, vol. 44, no. 8, Article ID W08413, 2008.

[30] S. Qiu, J. Wei, F. Pan, J. Liu, and A. Zhang, "Vibrational, NMR spectrum and orbital analysis of $3,3^{\prime}, 5,5^{\prime}$ - tetrabromobisphenol A: a combined experimental and computational study," Spectrochimica Acta-Part A: Molecular and Biomolecular Spectroscopy, vol. 105, pp. 38-44, 2013.

[31] J. Shang, C. Liu, and Z. Wang, "Transport and retention of engineered nanoporous particles in porous media: effects of concentration and flow dynamics," Colloids and Surfaces A: Physicochemical and Engineering Aspects, vol. 417, pp. 89-98, 2013.

[32] B. J. H. Matthews, A. C. Jones, N. K. Theodorou, and A. W. Tudhope, "Excitation-emission-matrix fluorescence spectroscopy applied to humic acid bands in coral reefs," Marine Chemistry, vol. 55, no. 3-4, pp. 317-332, 1996.

[33] J. J. Mobed, S. L. Hemmingsen, J. L. Autry, and L. B. Mcgown, "Fluorescence characterization of IHSS humic substances: total luminescence spectra with absorbance correction," Environmental Science and Technology, vol. 30, no. 10, pp. 3061-3065, 1996.

[34] M. J. Pullin and S. E. Cabaniss, "Rank analysis of the pHdependent synchronous fluorescence spectra of six standard humic substances," Environmental Science \& Technology, vol. 29, no. 6, pp. 1460-1467, 1995.

[35] R. W. P. M. Laane, "Influence of $\mathrm{pH}$ on the fluorescence of dissolved organic matter," Marine Chemistry, vol. 11, no. 4, pp. 395-401, 1982. 
[36] J. R. Wright and M. Schnitzer, "Metallo-organic interactions associated with podzolization," Soil Science Society of America Journal, vol. 27, no. 2, pp. 171-176, 1963.

[37] K. Ghosh and M. Schnitzer, "Fluorescence excitation spectra of humic substances," Canadian Journal of Soil Science, vol. 60, no. 2, pp. 373-379, 1980.

[38] T. D. Gauthler, E. C. Shane, W. F. Guerin, W. R. Seitz, and C. L. Grant, "Fluorescence quenching method for determining equilibrium constants for polycyclic aromatic hydrocarbons binding to dissolved humic materials," Environmental Science \& Technology, vol. 20, no. 11, pp. 1162-1166, 1986.

[39] M. U. Kumke, H.-G. Löhmannsröben, and T. Roch, "Fluorescence quenching of polycyclic aromatic compounds by humic acid," Analyst, vol. 119, no. 5, pp. 997-1001, 1994.

[40] M. M. de Souza Sierra, O. F. X. Donard, M. Lamotte, C. Belin, and M. Ewald, "Fluorescence spectroscopy of coastal and marine waters," Marine Chemistry, vol. 47, no. 2, pp. 127-144, 1994.

[41] EPA, Method 1614 Rominated Diphenyl Ethers in Water, Soil, Sediment and Tissue by HRGC/HRMS, 2007.

[42] A. R. Fontana, M. F. Silva, L. D. Martínez, R. G. Wuilloud, and J. C. Altamirano, "Determination of polybrominated diphenyl ethers in water and soil samples by cloud point extractionultrasound-assisted back-extraction-gas chromatography-mass spectrometry," Journal of Chromatography A, vol. 1216, no. 20, pp. 4339-4346, 2009.

[43] J. Llorca-Porcel, G. Martínez-Sánchez, B. Álvarez, M. A. Cobollo, and I. Valor, "Analysis of nine polybrominated diphenyl ethers in water samples by means of stir bar sorptive extraction-thermal desorption-gas chromatography-mass spectrometry," Analytica Chimica Acta, vol. 569, no. 1-2, pp. 113118, 2006.

[44] P. Zhang and Y. Wang, "Epi-fluorescence imaging of colloid transport in porous media at decimeter scales," Environmental Science \& Technology, vol. 40, no. 19, pp. 6064-6069, 2006.

[45] X. Liu, J. Li, Z. Zhao et al., "Solid-phase extraction combined with dispersive liquid-liquid microextraction for the determination for polybrominated diphenyl ethers in different environmental matrices," Journal of Chromatography A, vol. 1216, no. 12, pp. 2220-2226, 2009. 

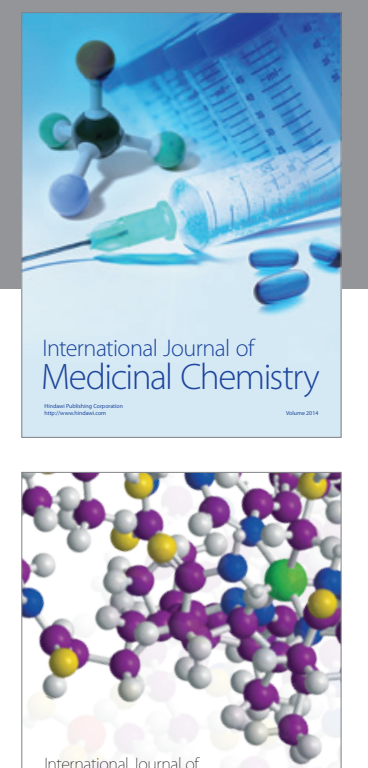

\section{Carbohydrate} Chemistry

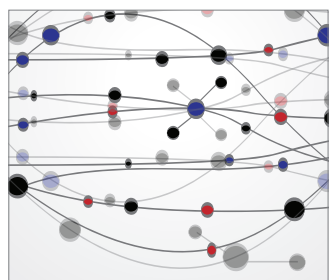

The Scientific World Journal
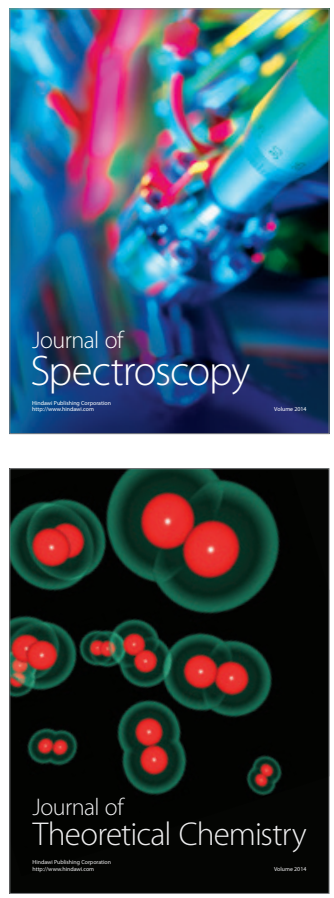
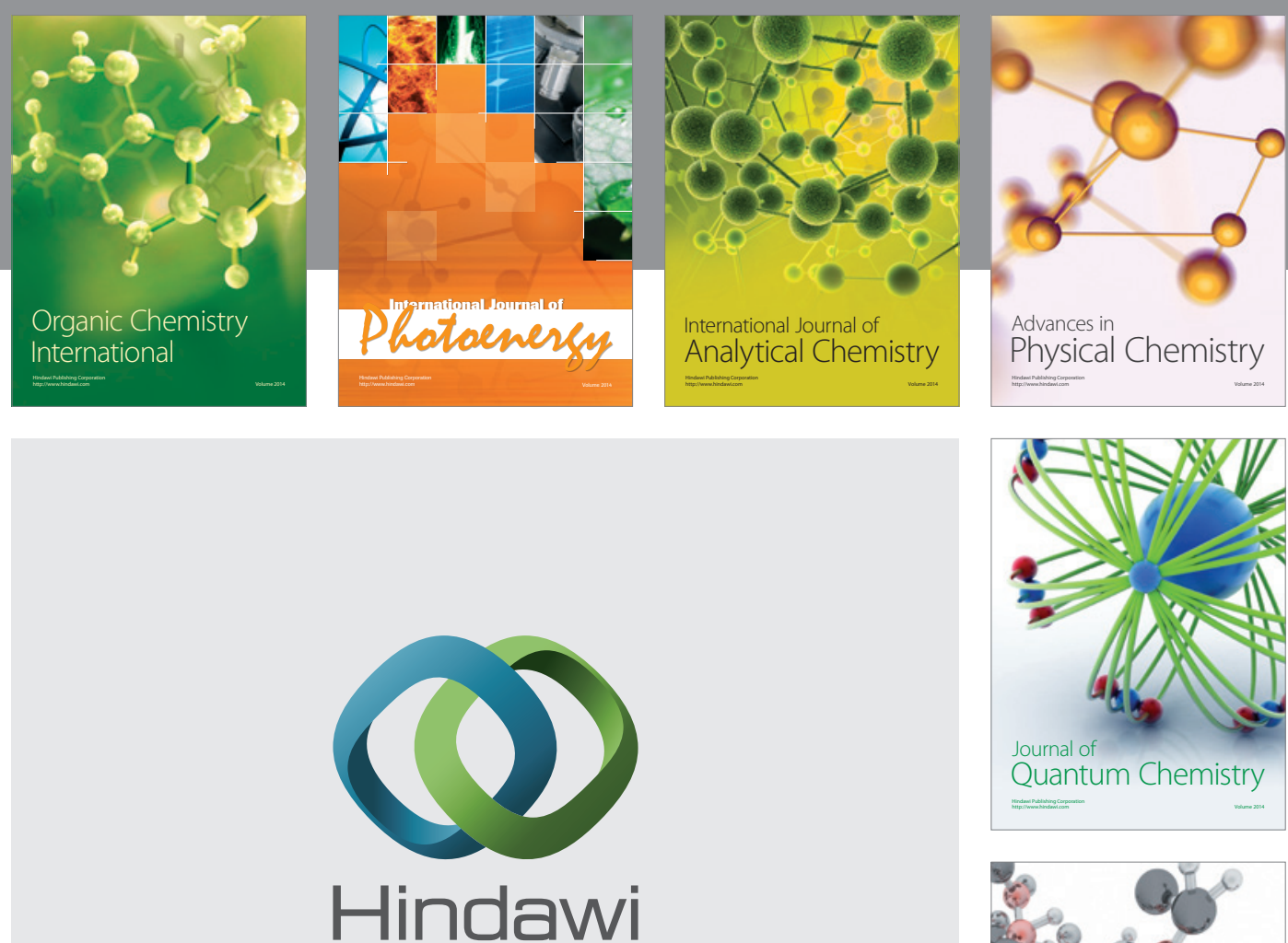

Submit your manuscripts at

http://www.hindawi.com

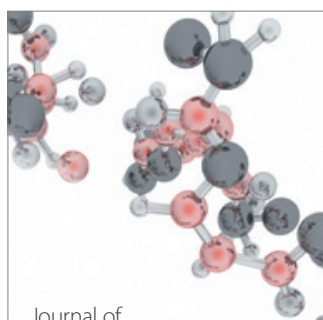

Analytical Methods

in Chemistry

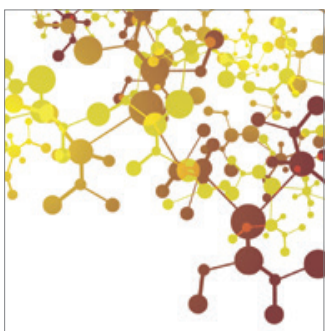

Journal of

Applied Chemistry

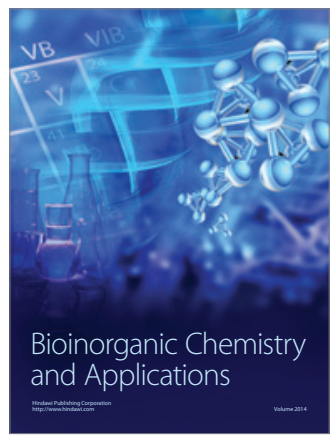

Inorganic Chemistry
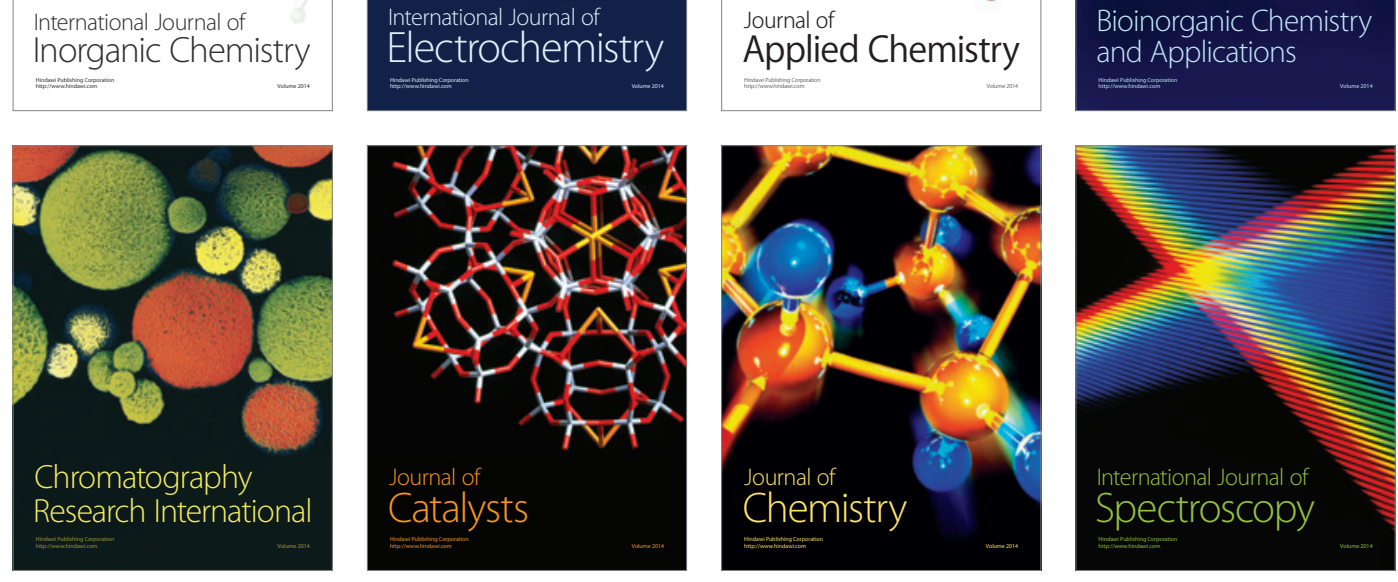